\title{
Current views on the indications and techniques for tonsillectomies in children

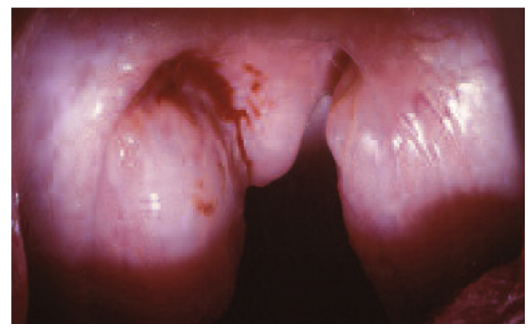

\author{
Martine FRANÇOIS
}

\section{ABSTRACT}

There are two principal indications for tonsillectomies or ablation of palatal tonsillar tissue: repeated episodes of tonsillitis lat least 5 times per year in two successive years) and obstructive tonsillar tissue as well as another, more rare, indication, highly asymmetrical blocs of tonsillar tissue that may suggest presence of a lymphoma. When tonsils are obstructive in patients suffering from sleep apnea, the indication for excision is formal and requires prompt attention. In other cases of enlarged tonsils the indication for surgery can be discussed but practitioners must inform parents of the possible maxillofacial complications that may develop because of chronic pharyngeal blockage.

Surgeons perform tonsillectomies on children under general anesthesia, protecting the lower airways by intubation. Post-operative pain after surgery is constant and practitioners must be prepared to manage it in conformity with the age of patients and the difficulties they have in swallowing.

\section{KEY WORDS}

Tonsillectomy,

Hypertrophied tonsillar tissues,

Recurrent tonsillitis,

Lymphoma,

Pain,

Sleep apnea. 


\section{1 - INTRODUCTION}

A tonsillectomy is an excision of palatal tonsillar tissue. This lymphoid tissue together with other components of Waldeyer's ring, adenoidal tissue and lingual tonsils, constitutes an individual's first line of defense against bacterial and viral invasions through the nasal and oral cavities but can, nevertheless, be removed with no resultant unfavorable immuno-allergic consequences ${ }^{7}$. Still, the surgical intervention can be painful and encumbered by some risks, essentially hemorrhagic. Therefore, the treatment team, in consultation with family members, must conduct a scrupulous cost/benefit analysis.

\section{2 - INDICATIONS FOR TONSILLECTOMY IN INFANTS}

\section{2 - 1 - Hypertrophied tonsils}

Practitioners must suspect any clear unilateral tonsillar hypertrophy, and assume it is pathological when it is triple the size of its contralateral mate, of being a lymphoma ${ }^{2}$, requiring rapid removal, within the week, for anatomo-pathological examination (fig. 1).

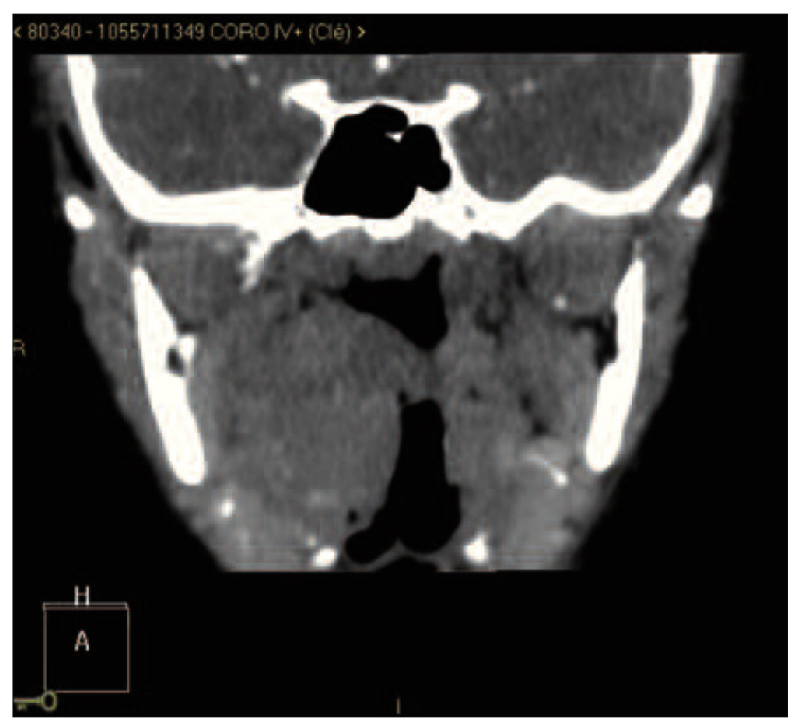

Figure 1

A computed tomodensitometric coronal section showing a very bulky right tonsillar mass that is a lymphoma.
Bilateral tonsillar hypertrophy is a benign growth of excess tissue caused by lack of timely apoptosis, or appropriate death of cells. This particular malady first widely recognized in the 1970s today constitutes almost half of the indications for tonsillectomy in infants ${ }^{15}$. It is primarily seen in children younger than 5 who otherwise enjoy good health. But indications for surgical intervention $^{6,18,19,20}$ are clear for children with enlarged tonsils who also suffer from sleep apnea. Tonsillectomy is also advisable for children who are mouth breathers in order to prevent unwelcome maxillofacial consequences such as opening the mandibular angle and creating an anterior open bite. When symptoms are minor, practitioners should adopt a posture of watchful waiting.

Critical signs include snoring and other nocturnal problems such as agitated sleep, with frequent leg movements and changes of position, adopting abnormal sleep postures such as genu pectoral or extreme hyperextension of the head, frequent calls to parents or visits to their bedrooms, sweating, or drooling. Practi- 
tioners should ask if patients sometimes stop breathing and then resume it with a noisy inspiration of air. Some parents have hit upon the good idea of making videos of their children's nocturnal behavior that can be effectively revelatory. Other, less noticeable symptoms, like morning headaches, agitated somnolence, difficulty in swallowing solids, and problems with maintaining attention may also be present. Severe cases of hypertrophied tonsils may cause interruption with the steady progress of weight gain and statural growth $^{14}$ (fig. 2).

Examiners may find the volume of tonsils of the oropharynx difficult to assess because of a child's natural gagging reflex that causes them to pivot inwards and appear larger than they actually are.

A diagnosis of pathological, but benign, enlargement can be made when tonsils are hypertrophied enough for right and left masses to abut or have less than a centimeter of separation in the absence of a nauseous reflex ${ }^{6}$ and are associated with typical symptoms (fig. 3). It is only in cases of imprecision of clinical signs, of neurological problems, or of the major operative risks associated with systemic disorders like hemophilia that practitioners need to order a nocturnal polysomnograph study to clarify the severity of obstructive sleep apnea with desaturation (fig. 4).

When the decision not to perform a tonsillectomy is made, after several months, or years, symptoms diminish because growth of the oropharynx has made the enlarged tissues occupy relatively less space or because the

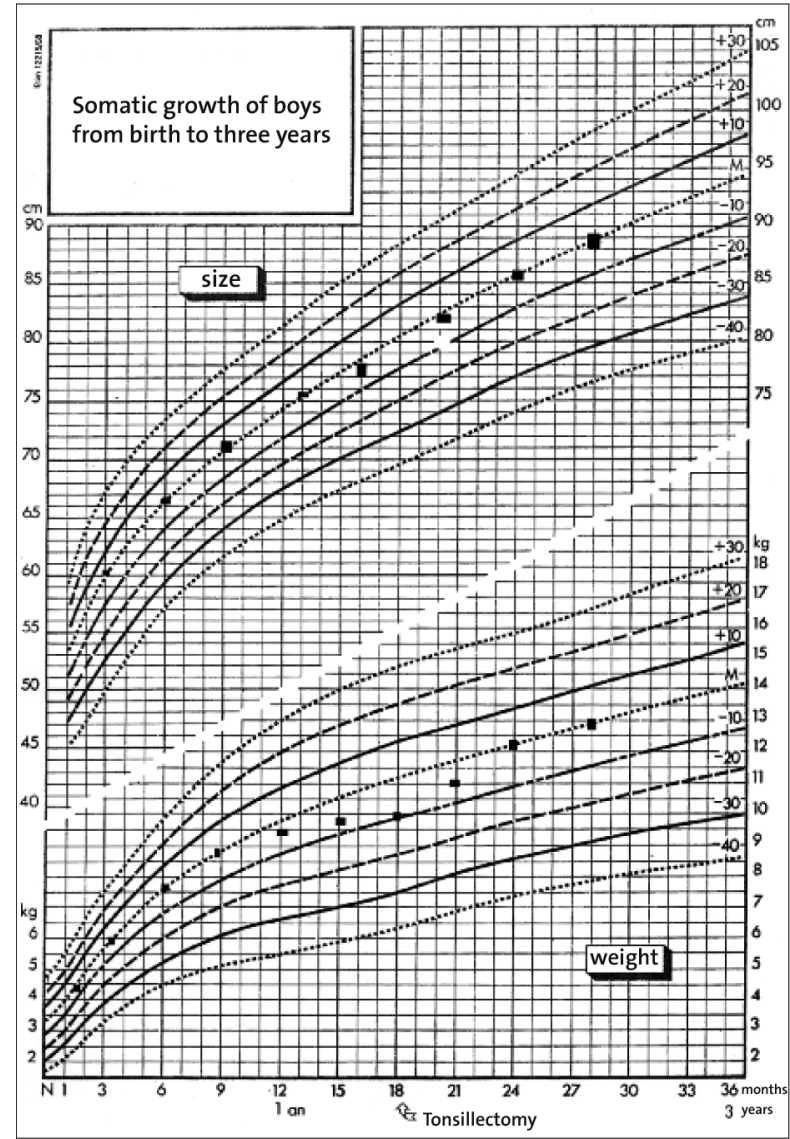

Figure 2

Stature and weight curves of a young boy with tonsillar obstruction. The weight curve began to flatten when he was 9 months old, the growth curve a little later. The child had a tonsillectomy at the age of 18 months and the weight and growth curves started to improve in the next few months.

tonsils themselves have shrunken as adolescence progresses. However, as long as the tonsils remain hypertrophied they block pharyngeal respiration and have a deleterious effect on the heart and brain that could cause irreversible lesions. And continued mouth breathing could have deleterious maxillofacial consequences ${ }^{18,20}$. 


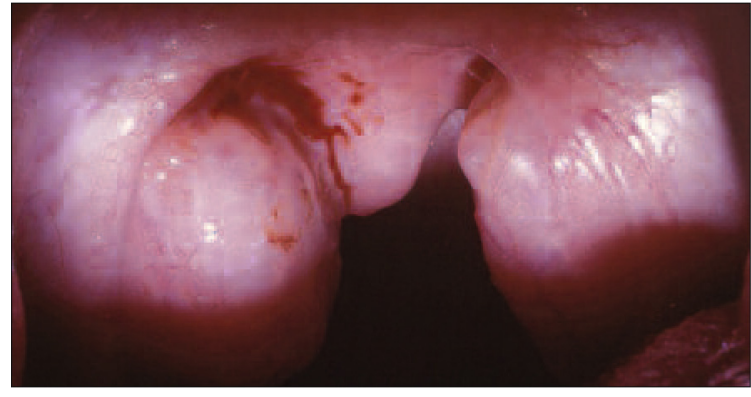

Figure 3

Normal sized palatal tonsils in a five year-old boy. There is more than a centimeter of space between the right and left free margins.

Treatment with corticoids will reduce tonsillar bulk, but only temporarily ${ }^{1}$. They are used to remove respiratory blockage from the enlarged tonsils that are caused by infectious mononucleosis. But no medication is capable of reducing the size of tonsils permanently so that the only solution to their hypertrophy is surgical excision $^{19}$.

\section{2 - 2 - Repeated attacks of tonsillitis}

Tonsillectomy is indicated when a child has had 7 episodes of tonsillitis in a single year or 5 in each of two successive years ${ }^{4,12,19}$. In their interview, practitioners should ask how many times children's' sore throats

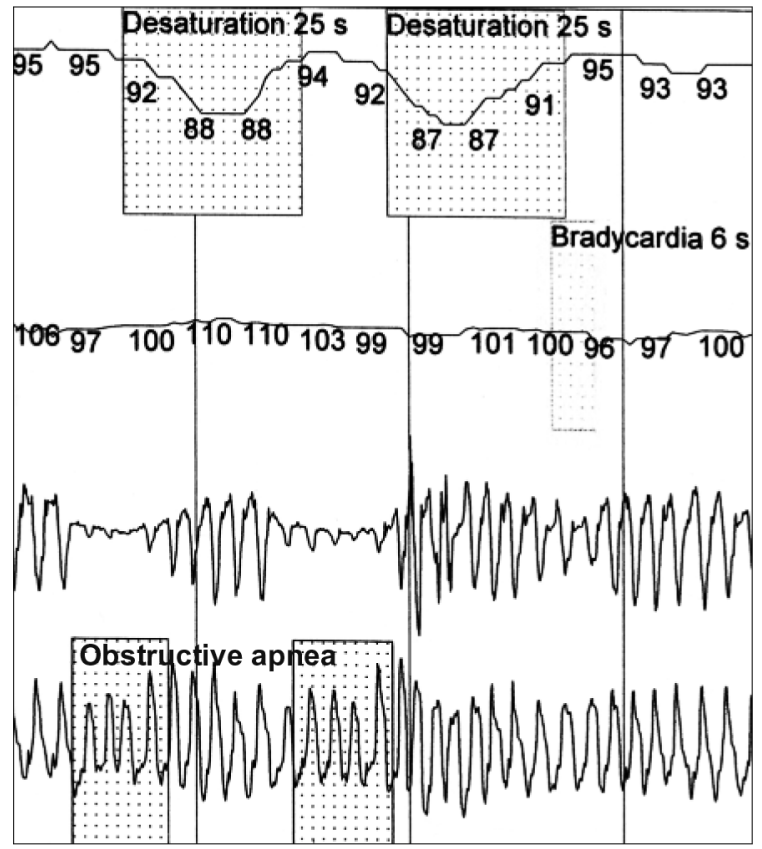

Figure 4

Polysomnograph registration showing desaturation associated with obstructive sleep apnea.

have required antibiotic treatment or their missing school.

In such cases surgical intervention is not obligatory but the practitioner should suggest its possibility. Parents may opt for symptomatic treatment of infections if the rapid strep test, RST, is positive. If operations are not performed, episodes of infection may begin to occur less frequently after several years.

\section{3 - TECHNIQUES FOR TONSILLECTOMY IN INFANTS}

No matter what technique is employed, surgeons perform all tonsillectomies for children under general anesthesia with oral or naso-tracheal intubation to protect the lower airways, gaining access through the mouth to avoid external scarring. 


\section{3 - 1 - Dissection is the technique most often utilized}

The surgeon gains access to the tonsils by passing instruments through the gap between the tonsillar capsule and the muscles that surround $i^{9}$. Surgeons have the choice of making incisions with scissors, a Jost comb (peigne de Jost), a curette, or an electric bistoury ${ }^{11,17}$. They can achieve hemostasis with a bipolar electric bistoury (the monopolar bistoury is not advisable) but sometimes supported sutures or pillar ligatures may also be needed.

Children operated on for repeated sore throats are considered ambulatory, that is they can return home if conditions are acceptable, meaning that two responsible adults should be present with access to a telephone in a site located where the hospital or clinic can be reached in less than half an hour ${ }^{5,15}$. But patients who have been operated on for removal of obstructive tonsils should not be considered ambulatory.

After the tonsillectomy patients suffer constant pain that is aggravated by swallowing ${ }^{2,13}$. So level 2, of the World Health Organization scale, analgesics should be prescribed to make the pain bearable and to allow the child to eat. Acetaminophen is insufficient and anti-inflammatories are contra-indicated.

Parents should provide their children with acceptable nourishment, cold, liquid or sometimes liquid mixed with solids. At the slightest indication of bleeding, parents should bring their children to the clinic or hospital promptly because unpredictable

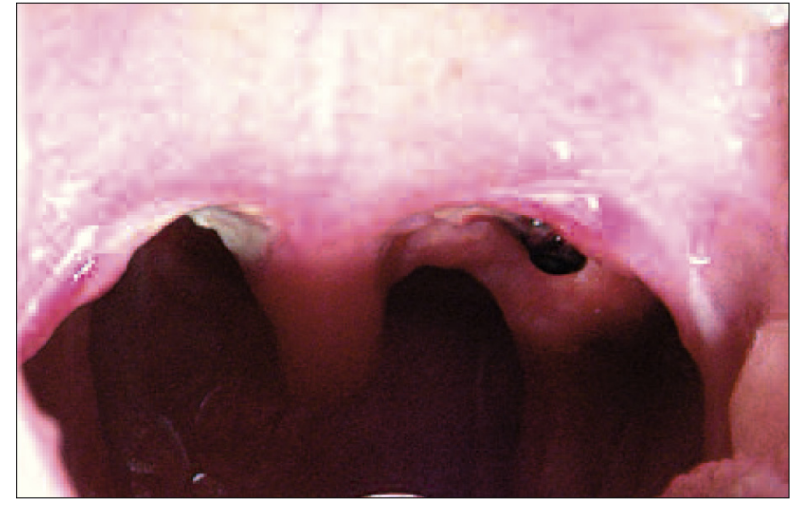

Figure 5

Hemorrhage occurring 10 days after a surgical tonsillectomy. A blood clot is visible in the upper pole of the left tonsillar fossa. Note that the right tonsillar fossa has not yet healed completely: false membranes are present.

bleeding is always a risk in the first 15 days after the tonsillectomy ${ }^{8}$ (fig. 5).

\section{3 - 2 - Other techniques}

Tonsillectomies accomplished by $\mathrm{CO}_{2}$ laser, with micro-debridement or by coblation are, in fact, partial tonsillectomies. With $\mathrm{CO}_{2}$ lasers surgeons can, in a step-by-step procedure, vaporize 30 to $40 \%$ of palatal tonsillar tissue, removing everything in the zone of the tonsillar crypts ${ }^{11}$ but by adding micro-debridement they can increase the extent of tonsillar removal to 80 to $90 \%$. The procedure is an intra-capsular exeresis that greatly reduces the risk of post-operative hemorrhage and the degree of post-operative pain because the peritonsillar muscles are neither stretched nor denuded ${ }^{10,17}$. Coblation combines the action of radio frequency with a conducting saline solution that transfers energy without producing heat. With this technique surgeons make an 
extra-capsular excision or simply reduce tonsillar volume. According to several published studies of small samples, this procedure is less painful and less likely to cause hemorrhage in patients than surgical dissection.

Repeated episodes of sore throat are the principal indication for the new tonsillectomy techniques and parents are likely to welcome them because they have heard of the pain and complications that frequently follow traditional surgical tonsillectomies. However, no technique can promise that it will not be followed by some post-operative pain or risk of bleeding. And it is important to note that in $15 \%$ of cases symptoms do not disappear or reappear later. Parents should be given the option of selecting a surgical dissection for removal of tonsils. And it should be remembered that surgeons cannot bill for two tonsillectomies in the same patient, so they will not want to perform any corrective procedures for a not entirely successful first intervention. There is also a problem of how to finance the investment required for executing the new techniques.

\section{REFERENCES}

1. Al-Ghamdi SA, Manoukian JJ, Morielli A, Oudjane K, Ducharme FM, Brouillette RT. Do systemic corticosteroids effectively treat obstructive sleep apnea secondary to adenotonsillar hypertrophy? Laryngoscope 1997;107:1382-7.

2. Baffier E, Quettier G, Crusson JC. L'enfant, I'amygdalectomie et la douleur. in : Profession Infirmière, 1997;56:24.

3. Berkowitz RG, Mahadevan M. Unilateral tonsillar enlargement and tonsillar lymphoma in children. Ann Otol Rhinol Laryngol 1999;108:876-9.

4. Discolo CM, Darrow DH, Koltai PJ. Infectious indications for tonsillectomy. Pediatr Clin North Am 2003:50:445-58.

5. François M. Retour au domicile après amygdalectomie. Correspondance en Médecine 2003:4:36-7.

6. Girard M, Frydman E, Bayart V, Pinlong E, Desfougères JC, Lesage V, Ployet MJ, et al. L'obstruction pharyngée d'origine amygdalienne chez l'enfant. Ann Otolaryngol Chir Cervicofac 1993;110:10-7.

7. Ikinciogullari A, Dogu F, Ikinciogullari A, Egin Y, Babacan A. Is immune system influenced by adenotonsillectomy in children? Int J Pediatr Otorhinolaryngol 2002;66:251-57.

8. Johnston DR, Gaslin M, Boon M, Pribitkin E, Rosen D. Postoperative complications of powered intracapsular tonsillectomy and monopolar electrocautery tonsillectomy in teens versus adults. Ann Otol Rhinol Laryngol. 2010;119:485-9.

9. Koempel JA. On the origin of tonsillectomy and the dissection method. Laryngoscope 2002;112: 15836.

10. Koltai PJ, Solares CA, Mascha EJ, Xu M. Intracapsular partial tonsillectomy for tonsillar hypertrophy in children. Laryngoscope 2002;112:17-9.

11. Magdy EA, Elwany S, el-Daly AS, Abdel-Hadi M, Morshedy MA. Coblation tonsillectomy: a prospective, double-blind, randomised, clinical and histopathological comparison with dissectionligation, monopolar electrocautery and laser tonsillectomies. J Laryngol Otol 2008;122:282-90. Epub 2007;Nov26.

12. Marshall T. A review of tonsillectomy for recurrent throat infection. Br J Gen Pract 1998;48:1331-5. 
13. Molony NC, Santana-Hernandez D, Wardrop PJ, Armstrong M, Moralee SJ. On which day is pain worst following adult tonsillectomy? Int J Clin Pract 1998;52:372-3.

14. Nieminen $P$, Löppönen $T$, Tolonen $U$, Lanning $P$, Knip M, Löppönen H. Growth and biochemical markers of growth in children with snoring and obstructive sleep apnea. Pediatrics 2002;109:e55.

15. Parodi $\mathrm{M}$ et al. Quelle est la pratique de l'amygdalectomie en France de nos jours ? Lettre d'ORL 2003;288:5.

16. Plant RL. Radiofrequency treatment of tonsillar hypertrophy. Laryngoscope $2002 ; 112: 20-2$.

17. Pruegsanusak K, Wongsuwan K, Wongkittithawon J. A randomized controlled trial for perioperative morbidity in microdebrider versus cold instrument dissection tonsillectomy. J Med Assoc Thai. 2010;93:558-65.

18. Ruboyianes JM, Cruz RM. Pediatric adenotonsillectomy for obstructive sleep apnea. Ear Nose Throat J 1996; 75:430-3.

19. Senez B, Laugier J, au nom du groupe de travail réuni par I'ANAES. Indications de l'adénoïdectomie et/ou de l'amygdalectomie chez l'enfant. Ann Otolaryngol Chir Cervicofac 1998;115:S22-S45.

20. Singer LP, Saenger P. Complications of pediatric obstructive sleep apnea. Otolaryngol Clin North Am 1990;23:665-76. 